Supplement of Earth Syst. Sci. Data, 11, 1839-1852, 2019

U Earth System

https://doi.org/10.5194/essd-11-1839-2019-supplement

(C) Author(s) 2019. This work is distributed under

the Creative Commons Attribution 4.0 License.

(c) (1)

¿ Science

亏Data

Supplement of

\title{
Global variability in belowground autotrophic respiration in terrestrial ecosystems
}

\section{Xiaolu Tang et al.}

Correspondence to: Wenjie Zhang (wenjie.zhang@uts.edu.au) and Sicong Gao (sicong.gao@student.uts.edu.au)

The copyright of individual parts of the supplement might differ from the CC BY 4.0 License. 
Figures

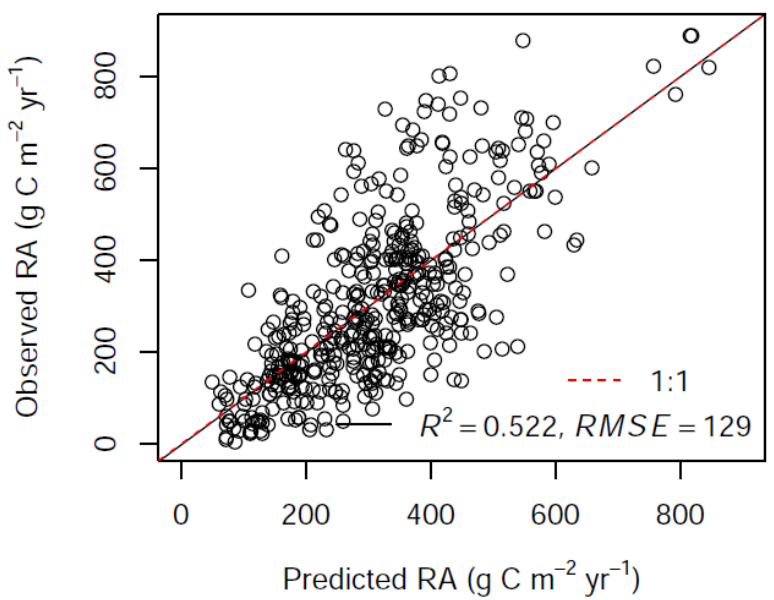

Fig. S1. Comparison between data-derived belowground autotrophic respiration (RA) and observed RA using a 10-fold crossvalidation. 

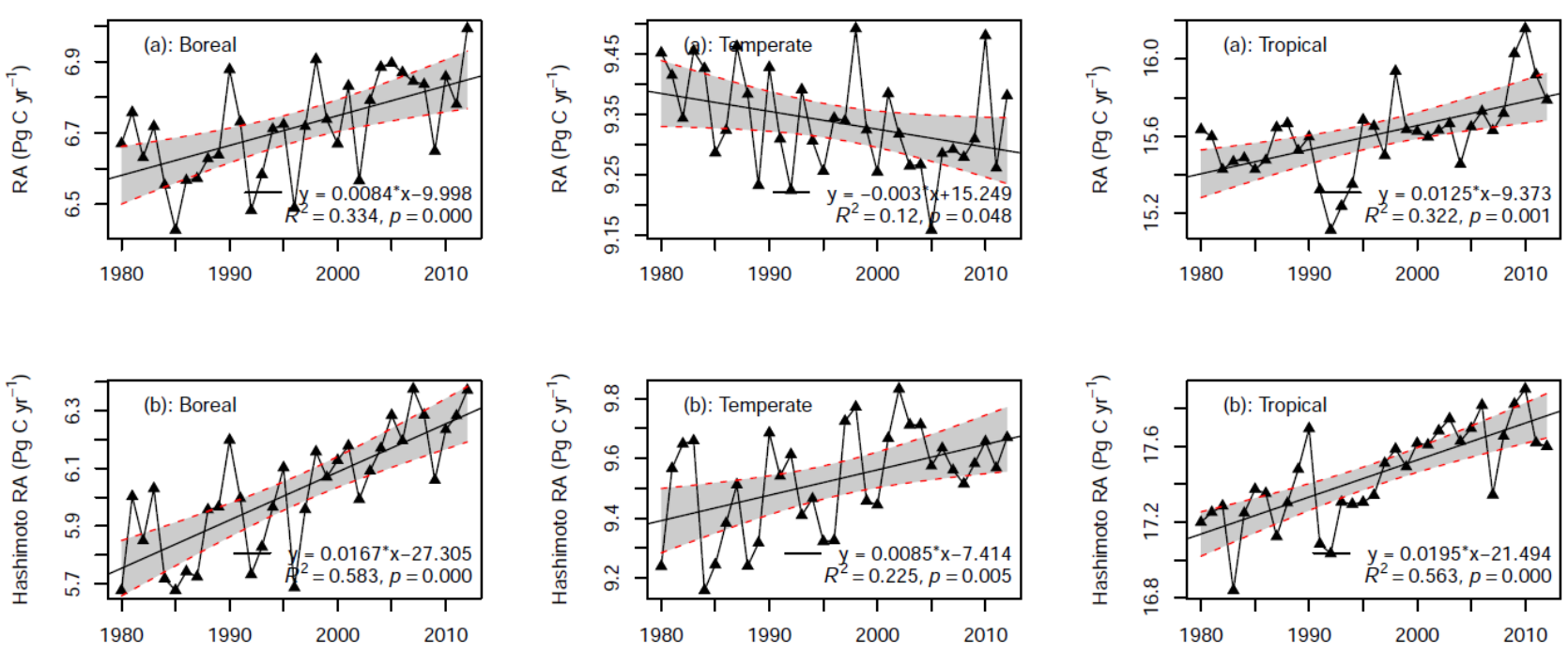

Fig. S2. Inter-annual variability of belowground autotrophic respiration (RA) for RF-RA (a) and Hashimoto2015-RA (b) for boreal, temporal and tropical areas 

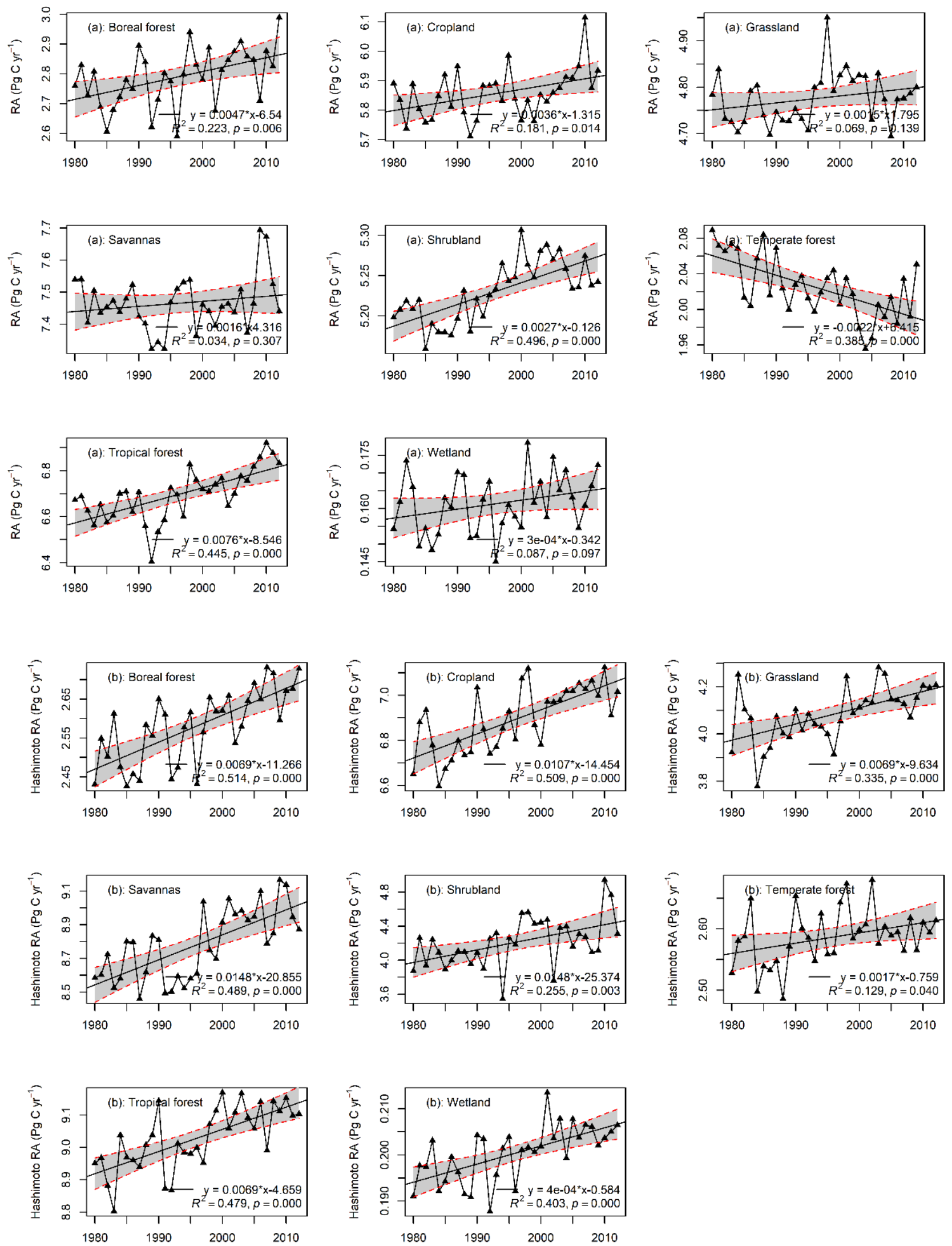

Fig. S3. Inter-annual variability of belowground autotrophic respiration (RA) for RF-RA (a) and Hashimoto2015-RA (b) for boreal forest, cropland, grassland, savannas, shrubland, temperate forest, tropical forest and wetland. 

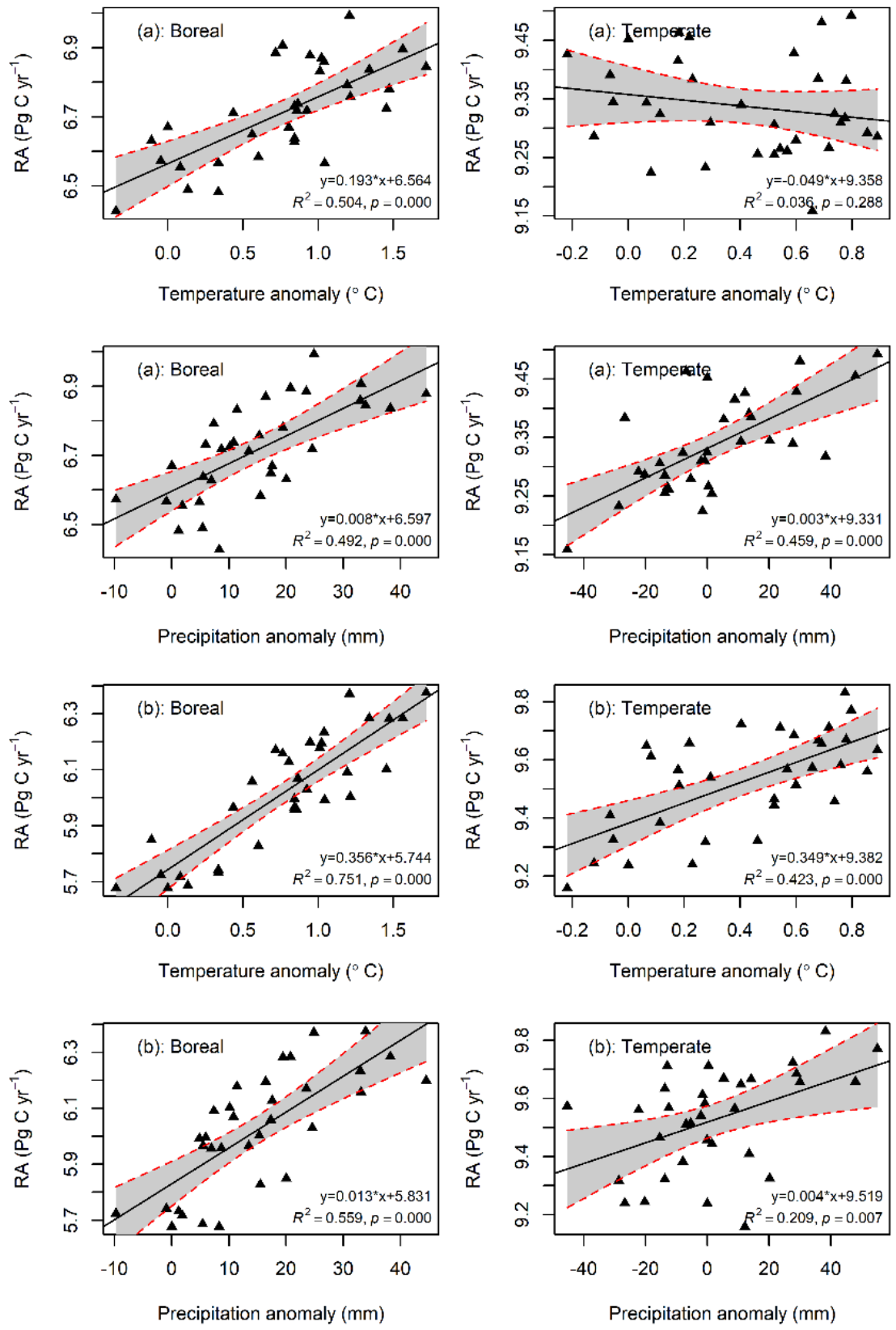
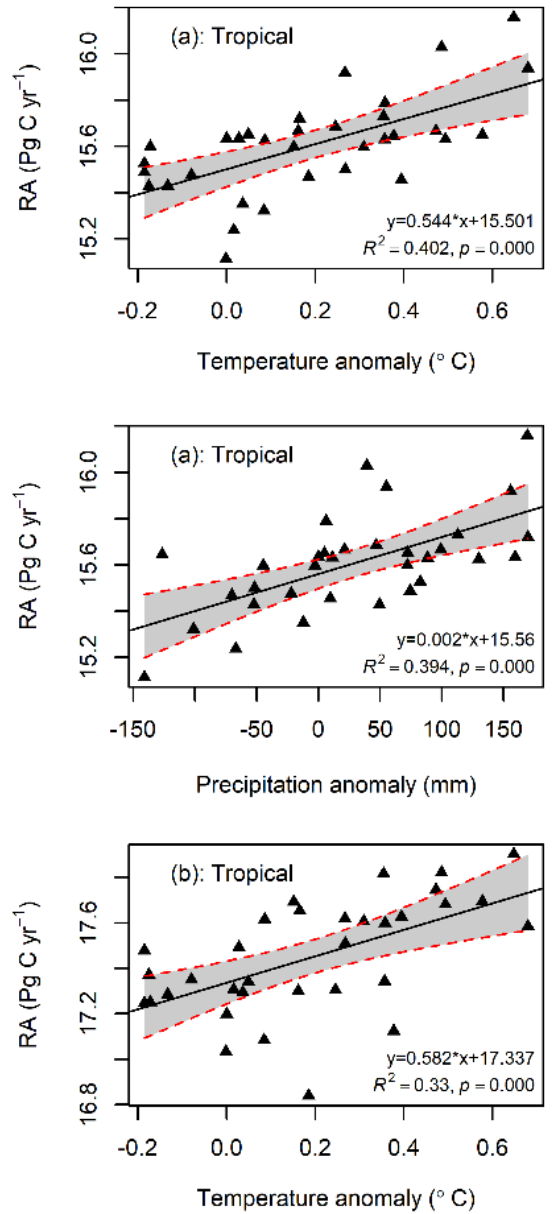

Fig. S4. The relationships between total belowground autotrophic respiration (RA) and temperature/precipitation anomaly for RF-RARF-RA (a) and Hashimoto2015-RA (b) for boreal, temperate and tropical areas. 

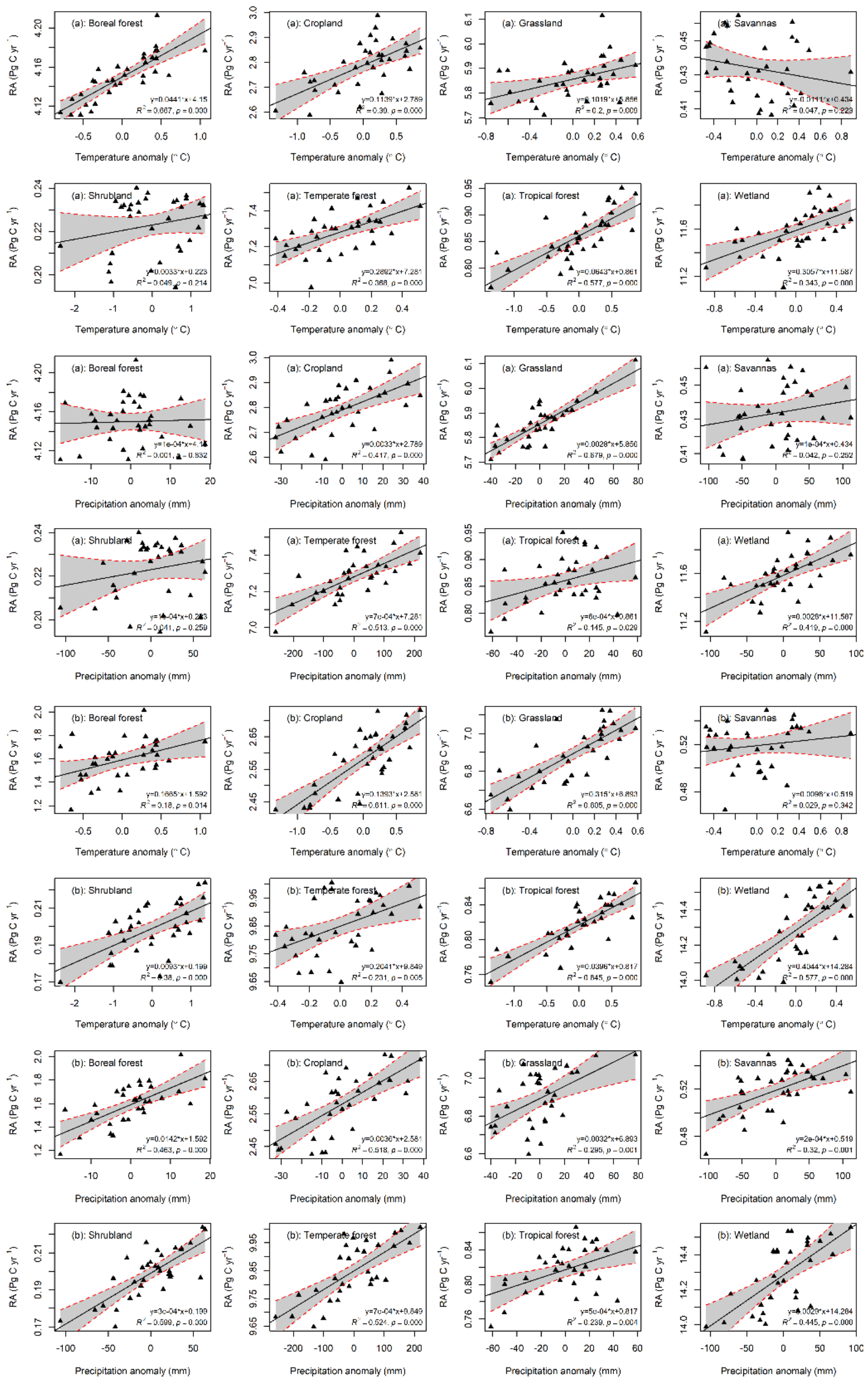

Fig. S5. The relationships between total belowground autotrophic respiration (RA) and temperature/precipitation anomaly for RF-RA (a) and Hashimoto2015-RA (b) for eight biomes 
MAP

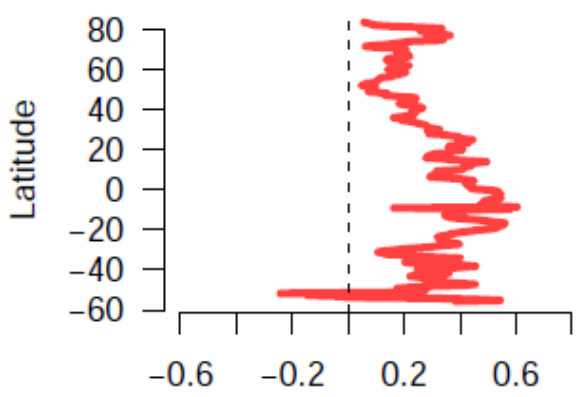

Partial correlation coefficient ( $r$ )
MAT

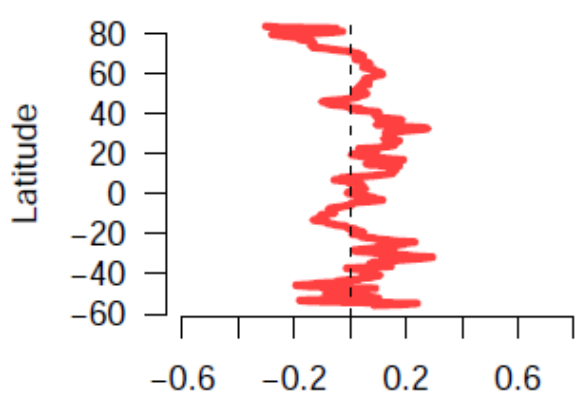

Partial correlation coefficient ( $r$ )

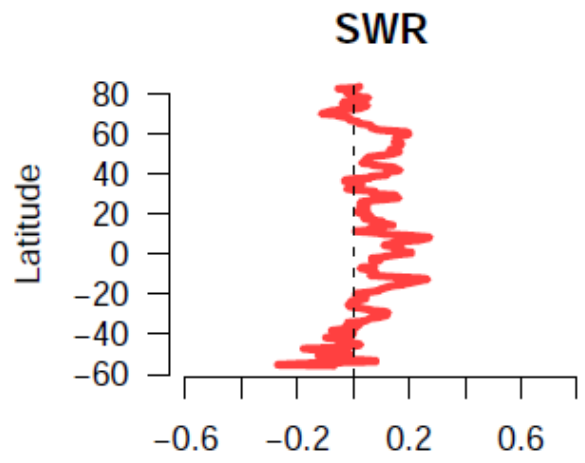

Partial correlation coefficient ( $r$ )

Fig. S6. Latitudinal patterns of partial correlation coefficient between RF-RA and mean annual temperature (MAT), mean annual precipitation (MAP) and shortwave radiation (SWR). 